Your leading article (24 February, p. 434) quotes the Department of Health and Social Security's memorandum HM(72) $71^{1}$ with regard to the elderly suffering from dementia and offers constructive criticism. It might be thought that $\operatorname{HM}(72) 71$, together with parts II and III of the Mental Health Act 1959 , is sufficient to deal with the crisis situations arising with the elderly. The scheme suggested in this letter would be a valuable addition and has the following advantages: (1)-action can be taken quickly; and (2)-the patient's mental condition need not be indicated-in order to qualify for action under parts II and III of the Mental Health Act the patient must be declared as suffering from mental disorder.

The social services could secure names of people willing to take on such tasks and, on the advice of the patient's doctor, he could be removed to their care. In emergency situations the move could be undertaken by the duty social services officer and the appropriate doctor be informed of this action.I am, etc., Barnsley Hall Hospital,

M. G. MCColI

1 National Health Service, Services for Mental illness related to Old Age, H.M.(72)71. London,
Department of Health and Social Security, 1972.

\section{Contraceptives on the N.H.S.}

SIR,-I would support Dr. T. D. Richards (28 April, p. 244) in his view that we should have a health-orientated Health Service. Making the doctor a contraceptive shopkeeper is to debase his standing, increase his work load, and strike a further blow in favour of the "no-morality society." It is the sick who need the physician.-I am, etc.,

Timperley, Cheshire

J. H. ScOtson

\section{Penicillin in Syphilis}

SIR,-To your admirable leading article on this subject (5 May, p. 259) may I be permitted to add two minor embellishments?

In the early enthusiastic days of penicillin era John Stokes, the doyen of American syphilologists, gave a timely word of warning: "From A.D. 1943, it will take a year to guess, two years to intimate, five years to indicate, a decade or more to know what penicillin does in syphilis." And now we know. It also seems that the quest for therapia sterilisans magna (the cure of syphilis by a single dose of a harmless drug) initiated by Paul Ehrlich early this century has been realized.-I am, etc.,

Perth

R. G. Simpson

1 Stokes, J. H., Beerman, H., and Ingraham, N. R Modern Clinical Syphilology, 3rd edn., p.
Philadelphia and London, Saunders, 1944.

\section{l}

Amoebiasis

SIR,-I was delighted to see the sane exposition of the amoebiasis situation by $\mathrm{Dr}$. R. G. Hendrickse (17 March, p. 669) but would like to emphasize and enlarge on some points.

The disease state is probably as abnormal for the amoeba as it is for the host. Normally Entamoeba histolytica is a com- mensal like the other intestinal amoebaeE. coli, E. hartmanni, Iodamoeba butschlii, and others. The Promethean concept originally propounded ${ }^{1}$ but later discarded ${ }^{2}$ by Dobell was unfortunately widely publicized on the other side of the Atlantic with unhappy results. ${ }^{3}$ Hoare ${ }^{4}$ finally disposed of the concept, and opinion has reverted to that propounded by Kuenen and Swellengrebel ${ }^{5}$ in 1913.

Distinction must be made between luminal amoebiasis and invasive amoebiasis. The only morphological criterion of invasive amoebiasis is the finding of haematophagous trophozoites. Diagnosis should not be based on the finding of cysts as these may be those of the harmless "Laredo" type, and in any case arise from commensal forms. Luminal amoebae do not give rise to antibodies, the detection of which forms a useful diagnostic point. As such antibodies persist long after invasion has ceased, their presence implies past or present tissue invasion. Their absence practically precludes either. A positive result is thus more significant in a nonendemic area such as Britain than it would be in a Durban African.-I am, etc.,

Amoebiasis Research Unit, Institute for Parasitology,

\section{B. ELSDON-DEW

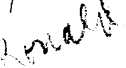
urban, South Africa

1 Dobell, C., fournal of Tropical Medicine and 2 Dobell, C., and Neal, R. A., Parasitology, 1952,

42, 16.
Elsdon-Dew, R., in Advances in Parasitology, 6. ed. B. Dawes. London, Academic Press,
1968.

4 Hoare, C. A., Experimental Parasitology, 1952, $1,+11$.
Kuenen

Kuenen, W. A., and Swellengrebel, N. H., Zentralblatt für Bakeriologie, Parasitenkunde, Infekionskrankheiten
originale, 1913, 71,378

\section{Acute Pancreatitis in Mycoplasma} pneumoniae Infections

SIR,-Drs. P.-A. Mårdh and B. Ursing (28 April, p. 240) described four cases of acute pancreatitis in which serological evidence of Mycoplasma pneumoniae infection was found.

When looking for serological evidence of viral infections in patients with acute pancreatitis we observed an unexpectedly high incidence of significant increases in $M$. pneumoniae complement-fixing antibodies during the illness. 1 Maximum increases in titre were from $<8$ up to 256 . Of 56 patients with acute pancreatitis, 18 showed a fourfold or greater increase, while 28 remained seronegative or had constant titres. In 10 patients the results varied from test to test, indicating anticomplementary activity between the antigen and antibody. No epidemiological fluctuation in the in cidence of acute pancreatitis could be observed when hospital records for the preceding three years were analysed. No cases of pneumonia occurred among the patients positive for $M$. pneumoniae. Nor did very high complement-fixing antibody titres $(<2,000)$, though this is a not infrequent phenomenon in $M$. pneumoniae pneumonia. These data led us to the conclusion that in these cases the reason for the antibody response is not $M$. pneumoniae but rather some antigenically related mycoplasma. ${ }^{2}$ Another explanation would be that during the course of acute pancreatitis cellular destruction leads to antigenic structures resembling those of $M$. pneumoniae. Anti- bodies to brain and lung tissue are known to develop in $M$. pnemoniae infections, ${ }^{3}$ suggesting a resemblance between the antigenic structures of $M$. pneumoniae and human tissue components.

Drs. Mårdh and Ursing do not give their criteria for the diagnoses of pneumonia. It would would be interesting to know whether the diagnoses were verified by $x$-rays in the survivors and, if so, whether the radiographs were characteristic. The other point of interest is whether the necropsy confirmed the diagnosis of mycoplasma pneumonia. In all cases an immune complex disease might explain the severely depressed respiratory exchange.-We are, etc.,

P. LEINIKKI P. PANTZAR

University of Helsinki,

Helsinki, Finland

1 Pantzar, P., Leinikki, P., and Tykkä, H., Biologie et Gastro-Entérologie, $1972,5,601 C .$,
Leinikki, P., Pantzar, P., and Tykkä, H., Scandinavian Ұournal of Gastroenterology. In press. Biberfeld, G., Clinical and Experimental Immuno-
logy, 1971, 8, 319 .

\section{Warfarin Dosage, Clofibrate, and Age of Patient}

SIR,-During analysis of results obtained during long-term oral warfarin therapy over a five-year period it was found that there was no significant correlation between the patient's age and the warfarin dose needed to maintain the plasma activated partial thromboplastin time (A.P.T.T.) between 50 and 70 seconds, a previously suggested therapeutic range. ${ }^{1}$ At the same time it was noticed that 25 patients with mitral valve disease treated with prophylactic warfarin required significantly less warfarin to produce this therapeutic response than did 255 patients treated with warfarin following venous thrombosis, myocardial infarction, or intracranial thromboses $(P<0.002)$

When warfarin dosage was analysed in patients treated with both warfarin and clofibrate following myocardial infarction the dose needed to maintain therapeutic prolongation of the A.P.T.T. and prothrombin time was significantly smaller than in patients with myocardial infarction treated with warfarin alone, as previously reported ${ }^{2}$ $(P<0.001)$. In addition, there appeared to be a significant inverse correlation between warfarin dosage and the age of the patient in 11 patients treated with warfarin plus clofibrate $(r=0.77$, being more than twice the corresponding standard error of distribution, making $\mathrm{P}<0.05$ ).

In this very small series of 11 patients treated with both warfarin and clofibrate the youngest patient was aged 31 years and the oldest was 49, which does not give a wide range of ages. Perhaps other clinicians with larger series may be interested in this possible relationship between warfarin dose and patient age, since the addition of clofibrate to warfarin therapy does require careful adiustment of warfarin dose to reduce the risk of haemorrhage. ${ }^{3}-\mathrm{I}$ am, etc.,

Frenchay Hospital,

R. D. EAstham

1 Eastham, R. D., British Medical fournal, 1968,

2 Oliver, M. F., et al., Lancet, 1963, 1. 143.

foumal, 1972, 87,'s. British Medico-Chirurgical 